\title{
The distribution of plasmids that carry virulence and resistance genes in Staphylococcus aureus is lineage associated
}

\author{
Alex J McCarthy ${ }^{*}$ and Jodi A Lindsay
}

\begin{abstract}
Background: Staphylococcus aureus is major human and animal pathogen. Plasmids often carry resistance genes and virulence genes that can disseminate through S. aureus populations by horizontal gene transfer (HGT) mechanisms. Sequences of $S$. aureus plasmids in the public domain and data from multi-strain microarrays were analysed to investigate (i) the distribution of resistance genes and virulence genes on S. aureus plasmids, and (ii) the distribution of plasmids between S. aureus lineages.

Results: A total of 21 plasmid rep gene families, of which 13 were novel to this study, were characterised using a previously proposed classification system. 243 sequenced plasmids were assigned to 39 plasmid groups that each possessed a unique combination of rep genes. We show some resistance genes (including ermC and cat) and virulence genes (including entA, ent $G$, entJ, entP) were associated with specific plasmid groups suggesting there are genetic pressures preventing recombination of these genes into novel plasmid groups. Whole genome microarray analysis revealed that plasmid rep, resistance and virulence genes were associated with S. aureus lineages, suggesting restriction-modification (RM) barriers to HGT of plasmids between strains exist. Conjugation transfer (tra) complex genes were rare.
\end{abstract}

Conclusion: This study argues that genetic pressures are restraining the spread of resistance and virulence genes amongst $S$. aureus plasmids, and amongst $S$. aureus populations, delaying the emergence of fully virulent and resistant strains.

\section{Background}

Methicillin-resistant Staphylococcus aureus (MRSA) are versatile and highly adaptive bacteria that are a major cause of hospital-associated (HA) infections, and are emerging to be a common cause of communityassociated (CA) and livestock-associated (LA) infections. Resistance to every antibiotic commonly prescribed is reported, and therefore the treatment and control of MRSA populations is difficult; this is of global concern. Resistance and virulence genes are often carried on mobile genetic elements (MGEs), such as bacteriophage, plasmids and transposons [1,2]. Dissemination of these genes through $S$. aureus populations by horizontal gene transfer (HGT) will lead to strains that are both more resistant and more virulent [1].

\footnotetext{
* Correspondence: amccarth@sgul.ac.uk

Centre for Infection, Division of Clinical Sciences, St George's, University of London, London, UK
}

Plasmids carry a diverse range of antimicrobial and biocide resistance genes and can carry toxin genes [2-4]. Resistances to antimicrobial agents carried by $S$. aureus plasmids include aminoglycosides, $\beta$-lactams and macrolides. Recently, the sequencing of S. aureus plasmids originating from different bacterial environments has revealed novel resistance genes, such as the apmA and $v g a C$ genes encoding resistance to apramycin and streptogramin A, respectively $[5,6]$. In addition, heavy metal resistance genes are often carried on plasmids [7]. Toxin genes carried on S. aureus plasmids include exotoxin B (ETB), a toxin that causes blistering of the skin, and the toxins EntA, EntG, EntJ and EntP [8].

The classification of plasmids has historically been determined by incompatibility groups based on the finding that two plasmids with the same replication (Rep) proteins cannot be stably maintained in the same cell $[9,10]$. More recently this method has been developed

\section{Biomed Central}


based on the sequence of the rep genes [11]. The sequence of a large number of plasmids isolated from $S$. aureus has now been released into the public domain; however there is currently no clear understanding of how virulence genes and resistance genes are linked to rep genes and plasmids. Such knowledge is fundamental in understanding the spread of resistance and virulence.

Additional barriers to the spread of plasmids between bacteria are the restriction-modification (R-M) systems. Two systems have been described in S. aureus; the type III R-M system protects bacteria against foreign DNA originating from other bacterial species [12], whilst the type I (SauI) R-M system protects bacteria against DNA originating from isolates of different $S$. aureus lineages [13]. The type I RM system consists of a restriction subunit (HsdR) and a modification subunit (HsdM) that can cleave and methylate DNA, and a specificity subunit (HsdS) that determines the specificity of the restriction and modification. Each lineage of $S$. aureus encodes unique sequence specificity $h s d S$ genes; and this means that DNA originating from different lineages by HGT is detected as foreign DNA and is digested, whilst DNA originating from the same lineage is detected as self DNA and remains undigested. Therefore, exchange of MGEs between lineages is infrequent [13]. Human $S$. aureus can be grouped into 10 major clonal complex (CC) lineages and many minor lineages [14]. Each lineage has a unique but highly conserved combination of genes encoding surface and secreted proteins [15]. However, there is much variation in the carriage of MGEs within a lineage suggesting that HGT is frequent within a $S$. aureus lineage [16,17].

Our specific aims of this study were (i) to extend the rep family classification to 243 sequenced S. aureus plasmids, (ii) to characterise the distribution of rep genes amongst the sequenced plasmids, (iii) to assess the distribution of 45 resistance and virulence genes between plasmids, and (iv) to investigate the distribution of plasmids between $254 \mathrm{~S}$. aureus isolates from 20 different lineages using microarray analysis. The overall aim was to better understand the dissemination of plasmids, resistance and virulence genes in S. aureus populations. We report 39 unique plasmid groups each with a unique combination of rep genes, and demonstrate that resistance and virulence genes are associated with plasmid groups and with lineage. Both of these findings suggest that genetic pressures are restraining the evolution of increasingly resistant and virulent $S$. aureus strains.

\section{Results}

\section{Characterisation of rep families}

A total of 21 rep families were assigned. 8 families $\left(\right.$ rep $_{5}$, $r e p_{7}, r e p_{10}, r e p_{10 b}, r e p_{13}, r e p_{15}, r e p_{16}$ and $\left.r e p_{19}\right)$ match those previously characterised by Jensen et al. [11]. 13 rep families are newly characterised in this study. 6 orphan rep sequences were also identified; in plasmids pAVX (repA_N domain), pWBG746 (repA_N domain), pWBG745 (repA_N domain), pKKS825 (rep_1 domain), pRJ6 (rep_3 domain), SAP099B (rep_2 domain).

\section{Plasmid groups possess unique combinations of rep genes}

A total of 39 plasmid groups of Staphylococcus aureus (pGSA) were assigned (Figure 1) based on the combination of rep genes each plasmid possessed. Each plasmid group had a unique combination of rep gene sequences. 6 of the 243 sequenced plasmids contain orphan rep sequences and were not assigned to a plasmid group. 18 plasmid groups carried 1 rep sequence, 17 plasmid groups carried 2 rep sequences and 4 plasmid groups carried 3 rep sequences. The large number of plasmid groups with more than $1 \mathrm{rep}$ gene indicates high levels of recombination between $S$. aureus plasmids. We note that in the majority of cases there was no difference in the length of a rep gene that appeared on single rep plasmids or multi-rep plasmids. The number of plasmids belonging to each plasmid group varied considerably (ranging from 1-32). The average length of plasmids belonging to plasmid groups varied (Figure 1). Nine plasmid groups have small genomes $(<5 \mathrm{~Kb})$ and carried few genes. 28 plasmid groups have large genomes $(>15 \mathrm{~Kb})$ and carried a diverse range of genes. 21 of these 28 large plasmid groups possessed more than 1 rep gene sequence. Many of these large plasmids carried rep genes found in small plasmids indicating recombination and integration of smaller plasmids. 13/243 plasmids carried plasmid conjugation transfer (tra) A-M genes. All plasmids from groups $p G S A_{6}, p G S A_{28}$ and $p G S A_{39}$ possessed traA-M genes, whilst plasmids from group $p G S A_{10}$ possess homologs of traE, traG and traI. Conjugation ability is therefore tightly linked with the replication machinery and rep sequences of rep $_{15}$ and rep ${ }_{21}$, respectively.

\section{Resistance genes and virulence genes are associated with plasmid groups}

The distribution of antimicrobial resistance, biocide resistance and heavy metal resistance genes found on plasmids was investigated (Additional file 1). The same resistance gene profile was found amongst all members of 16 plasmid groups (Figure 1). For example, small plasmids belonging to $p G S A_{3}$ all carried the ermC gene, and differed only by SNPs and insertions and deletions suggesting they are clonal (Figure 1 and Additional file 1). However, in 5 other small plasmid groups completely different resistance gene profiles existed. For example, the 30 plasmids belonging to the $p G S A_{2}$ plasmids carried either cat, tetK, str or vgaA. In contrast, larger 
plasmids carried more resistance genes, and 23 plasmid groups had more than one resistance gene profile. The majority of variation within these plasmid groups was due to the addition of resistance genes to a set of core conserved resistance genes or due to different combinations of the same resistances. For example, $p G S A_{7}$ plasmids carried blaZ and cadDX with or without aac/aph, aadE, aphA, bcrA, IP1, mphBM, qacA, sat and tcaA (Figure 1 and Additional file 1).

Toxin genes were rare amongst the sequence plasmids. ETB was only found in pETB. The genes entA, entG and entJ were tightly associated with $p G S A_{23}$ (present in 10 / 12 plasmids). These genes were also present in a single member of the $p G S A_{29}$ group suggesting that these genes can move to other plasmids. entP was associated with $p G S A_{32}$ (present in $4 / 6$ plasmids). Interestingly, these toxin genes were most frequently found on plasmids carrying more than 1 rep gene.

Some resistance genes had strong associations with particular rep genes and plasmid groups. The tetracycline resistance gene tetK was found in $p G S A_{2}$ plasmids indicating that the gene is tightly linked with the $\mathrm{rep}_{7}$ gene (Figure 1). The chloramphenicol resistance gene cat was found only in $p G S A_{2}, p G S A_{5}$ and $p G S A_{14}$ plasmids. Other resistance genes were not associated with particular rep genes or plasmid groups; arsC, blaZ, $\operatorname{cadDX}$, qacA.

\section{Microarray analysis reveals that rep, resistance and} virulence genes are associated with $S$. aureus lineage Microarray analysis showed that there was a differential distribution of 4/5 rep genes represented on the microarray $\left(r e p_{5}, r e p_{7}, r e p_{20}\right.$ and $\left.r e p_{25}\right)$ (Figure 2). rep 5 genes were found in isolates belonging to $S$. aureus lineages $\mathrm{CC} 15, \mathrm{CC} 25, \mathrm{CC} 30$ and $\mathrm{CC} 45$ but were rare in other major lineages. $\mathrm{rep}_{7}$ gene was commonly found in CC239 S. aureus, but was rare in other major lineages. rep $_{20}$ was found commonly in CC22 isolates. rep $_{25}$ was found $S$. aureus isolates belonging to lineages $\mathrm{CC} 1$, $\mathrm{CC} 15, \mathrm{CC} 22, \mathrm{CC} 30$ and $\mathrm{CC} 45$, but was rare in other 


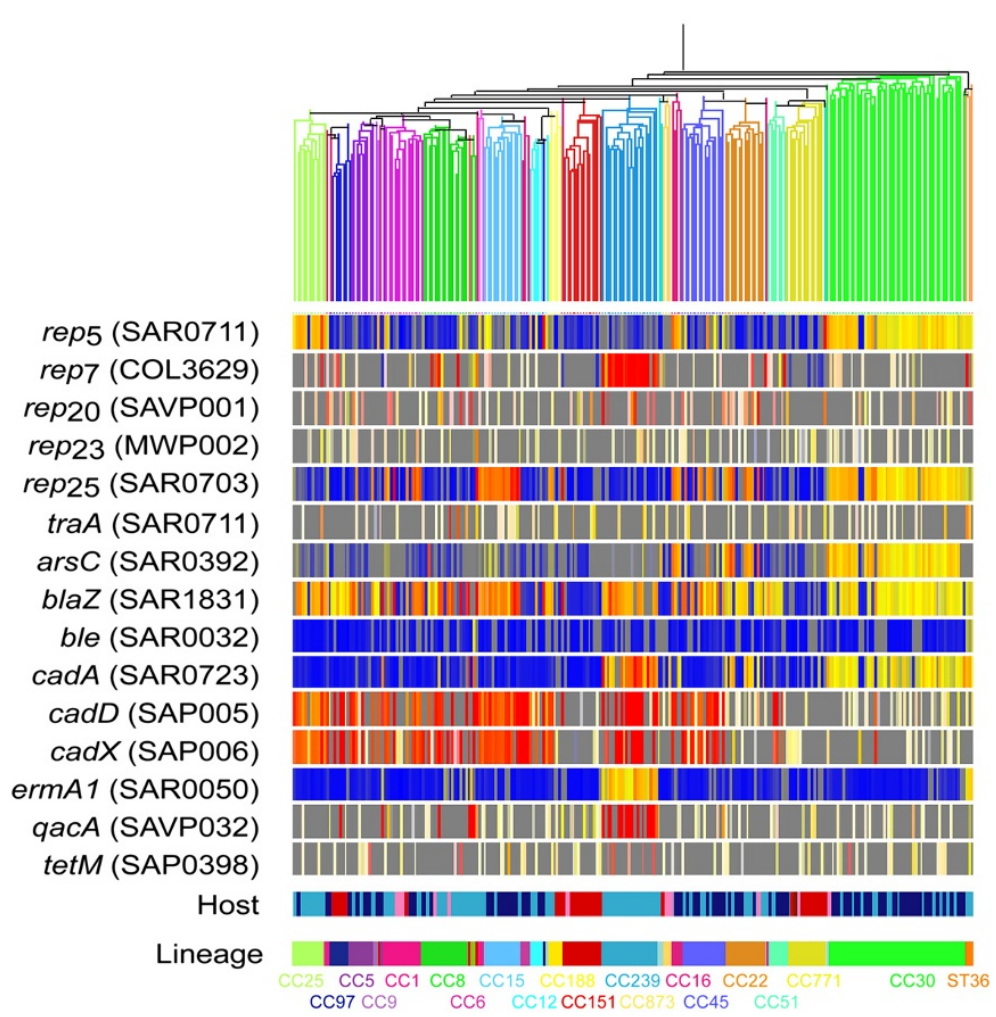

Figure 2 Distribution of plasmids in 254 S. aureus (198 human isolates and 55 animal isolates) using microarray. Presence or absence of each gene (listed on left) in each isolate is depicted by colour. The colour is an indicator of test signal over reference signal ratio. Thus, (i) yellow indicates presence of the gene in both test strain and reference strain, (ii) red indicates presence of the gene in the test strain but not in the reference strain, (iii) blue indicates absence in the test strain but not the reference strain, and (iv) grey indicates absence in both the test and reference strains. Genes with white signals are very low intensity and regarded as negative for both strains. The colour intensity is an indicator of signal intensity, and this can differ because (i) the homology of the probe, which can be hundreds of base pairs long, and DNA may vary, and (ii) copy numbers may vary. Isolates (represented vertically) are clustered into lineages [14]. For each isolate, its mammalian host of origin and its lineage (clonal complex) are shown at the bottom of the figure. Human isolates are coloured light blue (invasive) and dark blue (carriage). Animal isolates are coloured red (cow), pink (horse), maroon (sheep and goat) and white (camel). The figure shows that rep genes and resistance genes are distributed in a lineage dependent manner.

lineages. rep $_{23}$ were rare in all the $S$. aureus isolates included in our analysis. This analysis demonstrates an association of rep genes with $S$. aureus lineages. This is likely to be driven by both clonal expansion and by more frequent HGT within lineages than between lineages.

We also assessed the distribution of other plasmid genes between $S$. aureus lineages. The presence of plasmid conjugation transfer (tra)A-M genes was rare amongst the $S$. aureus isolates in our collection and was not associated with lineage (Figure 2). Interestingly, antimicrobial resistance genes and heavy metal resistance genes were associated to lineage. ars $C$ was common in MRSA CC22 and CC30 isolates, but rare amongst other lineages. blaZ was common in all human lineages of $S$. aureus but was rare in animal lineages of $S$. aureus. cadA presence was associated with MRSA CC22, CC30 and CC239 lineages, whilst cadDX was widely distributed and associated with 9 different lineages. ermA presence was associated with CC8 and CC239 lineages. qacA was associated with CC239 lineage. 2 of 9 (ble and tetM) resistance genes represented on the microarray are rare in the isolates we have analysed and were not distributed in a lineage dependent manner. We note that some of these genes may be carried on other elements or on integrated plasmids and this cannot be determined by microarray alone, for example tet $M$ can also be carried on transposons such as $\operatorname{Tn} 5801$.

\section{Discussion}

In this study we extended a previously proposed plasmid classification system to characterise rep genes from 243 plasmids that appear in the public domain [11]. We characterised $21 \mathrm{rep}$ families, of which 13 are newly described in this study. Whilst performing this analysis we noted that many plasmids carried more than one rep gene, we therefore assigned plasmids into groups based on the combination of rep genes carried. A total of 39 plasmid groups were assigned, and interestingly 20/39 
groups of sequenced plasmid carry more than one rep gene sequence. This indicates that recombination between S. aureus plasmids has occurred frequently. Recombination between $S$. aureus plasmids has been described, but the mechanisms and the frequency of such recombination events is not clearly understood [18]. Recombination should be a mechanism that transfers virulence and resistance genes into new plasmid groups.

The highly mosaic structure of plasmids seen suggests frequent recombination, but if this was completely random then resistance and virulence genes would not be associated to particular plasmid groups. Surprisingly, this was not the case. We found that some resistance and virulence genes were associated with plasmid groups; for example all $p G S A_{3}$ carried the ermC gene. This suggests there are tight associations between particular rep and resistance gene combinations. Resistance and virulence genes that had wider plasmid distributions were typically located on transposable elements that can "hop" between plasmids. This included blaZ located on Tn552 and $c a d D X$ on insertion sequence (IS) elements [19,20].

We also found evidence of movement of genes tightly linked to specific plasmids; (i) the virulence genes entA, ent $G$ and entJ are tightly linked with $p G S A_{23}$, but were also found in a single plasmid that belongs to $p G S A_{29}$, and (ii) the bacitracin resistance gene $b c r A$ that is tightly linked to the $p G S A_{7}$ plasmids, was also found in $1 / 12$ $p G S A_{23}$ plasmids. This argues that recombination can disseminate resistance and virulence genes into new plasmids, though this is rare.

Why is plasmid recombination not completely random? Recombination is likely to generate non-functional plasmids, or novel plasmids that cannot out-compete their parental plasmids. Because of the RM system it is possible that some plasmids do not come into contact because they are restricted to a small number of lineages. Some plasmids will be selected for because they provide a benefit to their hosts in specific environments. In addition, plasmids may be incompatible and this means that certain plasmids may not survive well in the same cell.

Indeed, this study also showed that the distribution of plasmids in $S$. aureus is lineage associated. This could limit the opportunities for plasmids in different lineages to recombine. There are two possible explanations for lineage associations of plasmids. Firstly, plasmids are distributed by clonal expansion and passed to daughter cells during replication. We found evidence that this occurs frequently, such as the CC239 isolates included in our analysis which represent a single dominant clone of invasive MRSA from a hospital in London, U.K. [21]. All isolates carried the same rep genes; this is evidence that clonal expansion can be a cause of plasmid distributions being lineage associated. Our conclusions are supported by the recent finding that USA300 (CC8) isolates carried highly conserved plasmids [22]. The second explanation is that plasmids are transferred between isolates frequently, but are blocked by efficient RM barriers, reducing transfer between isolates of different lineages. We found evidence that this occurs in S. aureus populations. Many plasmids were lineage associated but only found in some isolates, including those from different times and locations, indicating loss of plasmids as well as transfer.

The plasmids and resistances carried by our S. aureus isolates are reflective of the selective exposures existing in U.K. environments. Isolates originating from different countries may belong to different lineages and come into contact with the different exposures and carry different plasmids and resistances, or carry them at different frequencies [23]. Antibiotic usage and host specific plasmids are therefore also likely to have roles in controlling plasmid dissemination. The sequenced $S$. aureus plasmids may not be representative of all plasmid diversity, as they originate from a small number of lineages from only a few countries.

It is generally accepted that plasmids that contain the same origin of replication are incompatible and cannot survive within the same cell $[9,10]$. This study has identified a diverse range of rep genes and rep gene combinations. Biological tests are required to determine the incompatibility of plasmid groups, and to draw conclusions on the importance of this phenomenon in limiting plasmid recombination.

MGEs in other bacterial species may be additional sources of novel resistance and virulence genes that can move into $S$. aureus populations. Importantly, the vanA gene in vancomycin-resistant $S$. aureus (VRSA) isolates is carried on a transposon Tn1546 which is commonly found in vancomycin-resistant enterococci [24,25]. In some VRSA isolates the entire Enterococcal plasmid has been maintained, whilst in others $\operatorname{Tn} 1546$ has moved onto a Staphylococcal plasmid. Both genetic events suggest that enterococcal plasmid have successfully transferred into $S$. aureus bacteria. Future studies are required that assess the mosaicism of Staphylococcal and Enterococcal plasmids in order to understand the frequency of recombination and gene exchange between such bacterial species.

HGT mechanisms spread resistance and virulence genes between bacteria and populations. In $S$. aureus, two major HGT mechanisms have been described for plasmid movement (i) plasmid conjugation via the conjugation transfer (tra) complex, and (ii) bateriophage generalized transduction. In addition, it is possible that smaller plasmids can hitchhike larger plasmids that carry the tra complex and be transferred from donor to 
recipient bacteria [26]. We found that the tra genes were rare amongst the sequenced plasmids (13/243) and were rare amongst our collection of $254 \mathrm{~S}$. aureus isolates. Bacteriophage generalized transduction can transfer DNA fragments of less than $45 \mathrm{~Kb}$. We found that $96.7 \%$ of plasmids could theoretically be transferred by generalized transduction as they have genomes that are $<45 \mathrm{~Kb}$ in length. 6 of the 8 plasmids $>45 \mathrm{~Kb}$ in length carry the tra genes. Collectively, this data suggests that conjugative plasmids and plasmid conjugation are infrequent, and that bacteriophage transduction is likely to be the most frequent transfer mechanism of plasmids, particularly non-conjugative plasmids.

\section{Conclusion}

Plasmids are a principal driver of the spread of virulence and resistance genes in $S$. aureus populations via HGT, which is blocked by lineage specific R-M systems. This study has demonstrated that resistance and virulence genes are associated with plasmid groups, and that plasmids are associated with $S$. aureus lineage. This is evidence that genetic pressures and RM barriers are limiting the evolution of more resistant and more virulent $S$. aureus strains.

\section{Methods}

\section{Plasmid sequences}

A total of 243 sequenced S. aureus plasmids obtained from GenBank were included in analysis. 47 of these sequences are isolated from contigs of whole genome sequencing projects. GenBank accession numbers for all plasmid sequences are shown in Additional file 1. The lineage origin of plasmids is unknown for the majority of these plasmids, and therefore distributions of sequenced plasmid amongst lineages could not be investigated.

\section{rep gene assignment}

rep genes were identified by the presence of previously characterised protein replication domains (rep_1, rep_2, rep_3, repA_N, repL and rep_trans) using the proteinprotein BLAST search (www.ncbi.nlm.nih.gov/blast) [4]. Because rep genes can appear in truncated forms, those that encode proteins of less than 90 amino acids in length were not included in analysis. A rep family was assigned if two distinct rep gene sequences from two different plasmids shared at least $80 \%$ amino acid identity across the whole gene, as previously performed by Jensen et al. [11]. All rep families were named rep $p_{X}$ with the $X$ indicating the designated number of the family, and match those previously described by Jensen et al. 2009 . rep genes that were identified in only one S. aureus plasmids were termed rep orphans.

\section{Assignment of plasmid groups}

A plasmid group was assigned to each unique combination of rep genes found in a single sequenced plasmid. All plasmid groups were named $p G S A_{X}$ (for plasmid group of Staphylococcus aureus) with the $X$ indicating the designated number of the family. All members of the same plasmid group share the same rep gene or genes. Plasmid groups exist that possess a single rep gene. Other plasmid groups possess more than one rep gene.

\section{Distribution of resistance, virulence and transfer genes in S. aureus plasmids}

The distribution of genes carried on plasmids that have characterised or hypothesised roles in antimicrobial resistance $(n=29)$, biocide resistance $(n=3)$, heavy metal resistance $(n=5)$, transfer $(n=17)$, toxicity $(n=5)$ or adherence $(n=2)$ in sequenced plasmids was assessed by BLAST analysis of a representative gene sequence; a gene was present in a plasmid if there was $95 \%$ amino acid sequence identity. The genes and their characterised roles are shown in Table 1.

\section{Distribution of plasmid genes in S. aureus lineages}

In order to investigate the distribution of plasmid genes between $S$. aureus from diverse lineages we further analysed previous microarray data we generated from 254 human and animal S. aureus isolates of U.K. origin. The 198 human carriage and invasive isolates have been previously described and represent the major dominant lineages of $S$. aureus from hospitals and the community $[14,21,27]$. The 55 animal isolates have previously been described and originate from cows $(n=37)$, horses $(n=13)$, sheep $(n=2)$, goats $(n=2)$ and a camel $(n=1)$ [28]. The array design is available in B $\mu \mathrm{G} @ S b a s e$ (accession number: A-BUGS-17; httpbugs.sgul.ac.uk/A-BUGS17) and also ArrayExpress [28] and represents all the predicted ORFs from the first seven whole-genome $S$. aureus sequencing projects publically released, including five rep genes. Experiments were performed as previously reported [28]. The data used here is deposited in B $\mu G @ S b a s e$ (accession number: E-BUGS-62 and EBUGS-34) and also ArrayExpress (accession number: EBUGS-62 and E-BUGS-34).

Microarrays are an accurate, but not $100 \%$ accurate, way of determining presence and absence of individual genes in individual isolates using a single experiment. A full discussion of this accuracy is provided in Witney et al. [28]. Microarray heatmaps are an appropriate way to show microarray data as they accurately display the ratio of test signal and reference signal for each individual isolate. By analyzing multiple isolates from the same lineage it is possible to determine if genes are associated with individual lineages [14,27]. 
Table 1 Genes carried on plasmids involved in S. aureus survival and adaptation

\begin{tabular}{|c|c|c|c|}
\hline Gene Class & Gene & $\begin{array}{l}\text { Accession } \\
\text { Number/ } \\
\text { Locus Tag }\end{array}$ & Function \\
\hline \multirow{38}{*}{$\begin{array}{l}\text { Antimicrobial } \\
\text { resistance, } \\
\text { biocide resistance } \\
\text { and heavy metal } \\
\text { resistance }\end{array}$} & $\begin{array}{l}a a c A \\
a p h D\end{array}$ & VRA0030 & $\begin{array}{l}\text { Gentamicin \& Kanamycin } \\
\text { Resistance }\end{array}$ \\
\hline & $a a d D$ & PGO1_p21 & $\begin{array}{l}\text { Neomycin \& Kanamycin } \\
\text { Resistance }\end{array}$ \\
\hline & aadE & SAP049A_002 & Aminoglycoside Resistance \\
\hline & $a p h A$ & SAP049A_001 & $\begin{array}{l}\text { Neomycin \& Kanamycin } \\
\text { Resistance }\end{array}$ \\
\hline & $\operatorname{ars} C$ & SAP013A_020 & Arsenic Resistance \\
\hline & $b c r A$ & SAP049A_007 & Resistance to Bacitracins \\
\hline & blaz & pBORa53p07 & Penicillin Resistance \\
\hline & ble & PGO1_p20 & Bleomycin Resistance \\
\hline & cadA & SATW20_p1220 & Cadmium Resistance \\
\hline & cadDX & pKH18_01_02 & Cadmium Resistance \\
\hline & cat & pTZ4_p2 & $\begin{array}{l}\text { Chloramphenicol } \\
\text { Resistance }\end{array}$ \\
\hline & $c f r$ & EF450709 & $\begin{array}{l}\text { Chloramphenicol, } \\
\text { Lincosamides \& } \\
\text { Linezolid Resistance }\end{array}$ \\
\hline & $d f r A$ & PGO1_p48 & Trimethoprim Resistance \\
\hline & $d f r k$ & FN377602 & Trimethoprim Resistance \\
\hline & ermB & SAP013A_023 & MLS Group Resistance \\
\hline & ermC & pKH19_p2 & MLS Group Resistance \\
\hline & fos $B$ & pTZ2162_25 & Fosomycin Resistance \\
\hline & fus $B$ & pUB101_p23 & Fusidic Acid Resistance \\
\hline & $\mid P 1$ & pBORa53p09 & Immunity Protein \\
\hline & IP2 & SAP099A_005 & Immunity Protein \\
\hline & $\operatorname{lin} A$ & pKH21_p2 & Linezolid Resistance \\
\hline & mco & SAP019A_028 & Copper Resistance \\
\hline & merA & SAP026A_033 & Mercury Resistance \\
\hline & mphBM & SAP052A_035 & Macrolide Resistance \\
\hline & mupA & SAP082A_042 & Mupirocin Resistance \\
\hline & qacA & SAP066A_020 & Biocide Resistance \\
\hline & gacc & VRA0026 & Biocide Resistance \\
\hline & qac」 & pNVH01_p2 & Biocide Resistance \\
\hline & sat & SAP049A_002 & Streptothricin Resistance \\
\hline & str & pS194_p1 & Streptomycin Resistance \\
\hline & $t c a A$ & SAP082A_032 & Teichoplanin Resistance \\
\hline & tetk & pKH17_02 & Tetracycline Resistance \\
\hline & tetL & FN377602 & Tetracycline Resistance \\
\hline & tetM & SAPIG0957 & $\begin{array}{l}\text { Tetracycline \& Minocycline } \\
\text { Resistance }\end{array}$ \\
\hline & $\operatorname{van} B$ & VRA0040 & Vancomycin Resistance \\
\hline & vatA & M36022 & Streptogramin Resistance \\
\hline & $\operatorname{vgaA}$ & pVGA_p2 & Streptogramin Resistance \\
\hline & $v g a B$ & U82085 & Streptogramin Resistance \\
\hline
\end{tabular}

Table 1 Genes carried on plasmids involved in S. aureus survival and adaptation (Continued)

\begin{tabular}{|c|c|c|c|}
\hline \multirow[t]{18}{*}{ Transfer } & $\operatorname{traA}$ & SAP082A_013 & Plasmid conjugation \\
\hline & $\operatorname{traB}$ & SAP082A_012 & Plasmid conjugation \\
\hline & trac & SAP082A_011 & Plasmid conjugation \\
\hline & $\operatorname{traD}$ & SAP082A_010 & Plasmid conjugation \\
\hline & traE & SAP082A_009 & Plasmid conjugation \\
\hline & traF & SAP082A_008 & Plasmid conjugation \\
\hline & traG & SAP082A_007 & Plasmid conjugation \\
\hline & $\mathrm{traH}$ & SAP082A_006 & Plasmid conjugation \\
\hline & tral & SAP082A_005 & Plasmid conjugation \\
\hline & tras & SAP082A_004 & Plasmid conjugation \\
\hline & trak & SAP082A_003 & Plasmid conjugation \\
\hline & tral & SAP082A_002 & Plasmid conjugation \\
\hline & tram & SAP082A_001 & Plasmid conjugation \\
\hline & $\begin{array}{l}\text { type III } \\
\text { R-M }\end{array}$ & SAP039A_002 & $\begin{array}{l}\text { Prevents Survival of } \\
\text { Foreign DNA } \\
\text { in Host Bacterium }\end{array}$ \\
\hline & mob-l & AF447813 & Mobilisation L gene \\
\hline & $\operatorname{cas} 3$ & SAP039A_001 & $\begin{array}{l}\text { Helicase of the } \\
\text { CRISPR region }\end{array}$ \\
\hline & abik & SAP058A_004 & $\begin{array}{l}\text { Prevents Bacteriophage } \\
\text { Replication }\end{array}$ \\
\hline & C55 & pETB_p42 & $\begin{array}{l}\text { Lantibiotic System } \\
\text { that Kills } \\
\text { other Bacteria }\end{array}$ \\
\hline \multirow[t]{5}{*}{ Toxins } & ETB & pETB_p01 & Toxin \\
\hline & ent $A$ & SAP048A_010 & Toxin \\
\hline & entG & SAP048A_007 & Toxin \\
\hline & ents & SAP048A_008 & Toxin \\
\hline & entP & SAP099A_058 & Toxin \\
\hline \multirow[t]{2}{*}{ Adherence } & sdrE & SAP041A_028 & Adherence to Host Cells \\
\hline & $\begin{array}{l}\text { Anti- } \\
\text { adhesin }\end{array}$ & SAP057A_026 & Prevents Adherence \\
\hline
\end{tabular}

$\overline{M L S}$, Macrolide \& Streptogramins. CRISPR, clustered regularly interspaced short palindromic repeats.

\section{Additional file}

Additional file 1: Distribution of rep, resistance, transfer, toxin and adherence genes in sequenced plasmids. Description: Presence of rep genes in all sequenced plasmids is shown by a black box, whilst a white box indicates absence. Plasmids are classified into plasmid groups by the combination of rep sequences that they carry. The presence of resistance, transfer, toxin and adherence genes is shown by "Y". Plasmids that originate from a whole genome sequencing contig are marked by *

\section{Acknowledgements}

We are grateful to Anne Summers and Julie Shearer (University of Georgia, Athens, GA USA) for releasing plasmid sequencing data in advance of publication. We acknowledge Jason Hinds, Kate Gould, Denise Waldron and Adam Witney from the B $\mu \mathrm{G} @$ S group (the Bacterial Microarray Group at St 
George's, University of London) for microarray support and The Wellcome Trust for funding the multi-collaborative microbial pathogen microarray facility under its Functional Genomics Resources Initiative. This study was supported by the PILGRIM FP7 Grant from the EU.

\section{Authors' contributions}

AJM participated in study design, performed all analysis and drafted the manuscript. JAL participated in the study design and manuscript revisions. All authors read and approved the final manuscript.

\section{Authors' information}

AJM is a Post-Doctoral Research Fellow at St George's, University of London interested in pathogen evolution and host-pathogen interactions of bacteria and viruses. JAL is a Reader in Microbiol Pathogenesis interested in S. aureus.

Received: 11 October 2011 Accepted: 12 June 2012

Published: 12 June 2012

\section{References}

1. Lindsay JA: Genomic variation and evolution of Staphylococcus aureus. Int J Med Microbiol 2010, 300:98-103.

2. Malachowa N, DeLeo FR: Mobile genetic elements of Staphylococcus aureus. Cell Mol Life Sci 2010, 67:3057-3071.

3. Yamaguchi T, Hayashi T, Takami H, Ohnishi M, Murata T, Nakayama K, Asakawa K, Ohara M, Komatsuzawa H, Sugai M: Complete nucleotide sequence of a Staphylococcus aureus exfoliative toxin B plasmid and identification of a novel ADP-ribosyltransferase, EDIN-C. Infect Immun 2001, 69:7760-7771.

4. Jensen SO, Lyon BR: Genetics of antimicrobial resistance in Staphylococcus aureus. Future Microbiol 2009, 4:565-582

5. Kadlec K, Schwarz S: Novel ABC transporter gene, vga $(C)$, located on a multiresistance plasmid from a porcine methicillin-resistant Staphylococcus aureus ST398 strain. Antimicrob Agents Chemother 2009, 53:3589-3591

6. Fessler AT, Kadlec K, Schwarz S: Novel apramycin resistance gene apmA in bovine and porcine methicillin-resistant Staphylococcus aureus ST398 isolates. Antimicrob Agents Chemother 2011, 55:373-375.

7. Silver S, Phung LT: Bacterial heavy metal resistance: new surprises. Annu Rev Microbiol 1996, 50:753-789.

8. Jackson MP, landolo JJ: Cloning and expression of the exofoliative toxin B gene from Staphylococcus aureus. J Bacteriol 1986, 166:574-580

9. Novick RP: Plasmid incompatibility. Microbiol Rev 1987, 51:381-395.

10. Projan SJ, Novick R: Comparative analysis of five related Staphylococcal plasmids. Plasmid 1988, 19:203-221.

11. Jensen LB, Garcia-Migura L, Valenzuela AJS, Løhr, Hasman H, Aarestrup FM: A classification system for plasmids from enterococci and other Grampositive bacteria. J Microbiol Methods 2010, 80:24-43.

12. Corvaglia $A R$, François $P$, Hernandez D, Perron $K$, Linder $P$, Schrenzel J: A type III-like restriction endonuclease functions as a major barrier to horizontal gene transfer in clinical Staphylococcus aureus strains. Proc Natl Acad Sci U S A 2010, 107:11954-11958.

13. Waldron DE, Lindsay JA: Sau1: a novel lineage-specific type I restrictionmodification system that blocks horizontal gene transfer into Staphylococcus aureus and between S. aureus isolates of different lineages. J Bacteriol 2006, 188:5578-5585.

14. Lindsay JA, Moore CE, Day NP, Peacock SJ, Witney AA, Stabler RA, Husain SE, Butcher PD, Hinds J: Microarrays reveal that each of the ten dominant lineages of Staphylococcus aureus has a unique combination of surfaceassociated and regulatory genes. J Bacterio/ 2006, 188:669-676.

15. McCarthy AJ, Lindsay JA: Genetic variation in Staphylococcus aureus surface and immune evasion genes is lineage associated: implications for vaccine design and host-pathogen interactions. BMC Microbiol 2010, 10:173.

16. McCarthy AJ, Witney AA, Lindsay JA: Staphylococcus aureus temperate bacteriophage: carriage and horizontal gene transfer is lineage associated. Front Cell Inf Microbio 2011, 2:6.

17. McCarthy AJ, Lindsay JA: Detection of mobile genetic element (MGE) variation between colonizing and infecting hospital-associated (HA)MRSA isolates. J Clin Micro 2012, 50:1073-1075.
18. Gennaro ML, Kornblum J, Novick RP: A site-specific recombination function in Staphylococcus aureus plasmids. J Bacterio/ 1987, 169: 2601-2610.

19. Rowland SJ, Dyke KG: Characterisation of the staphylococcal betalactamase transposon Tn552. EMBO J 1989, 8:2761-2773.

20. O'Brien FG, Price C, Grubb WB, Gustafson JE: Genetic characterisation of the fusidic acid and cadmium resistance determinants of Staphylococcus aureus plasmid pUB101. J Antimicrob Chemother 2002, 50:313-321.

21. Edgeworth JD, Yadegarfar G, Pathak S, Batra R, Cockfield JD, Wyncoll D, Beale R, Lindsay JA: An outbreak in an intensive care unit of a strain of methicillin-resistant Staphylococcus aureus sequence type 239 associated with an increased rate of vascular access device-related bacteremia. Clin Infect Dis 2007, 44:493-501.

22. Kennedy AD, Porcella SF, Martens C, Whitney AR, Braughton KR, Chen L, Craig CT, Tenover FC, Kreiswirth BN, Musser JM, DeLeo FR: Complete nucleotide sequence analysis of plasmids in strains of Staphylococcus aureus clone USA300 reveals a high level of identity among isolates with closely related core genome sequences. J Clin Microbiol 2010, 48:4504-4511.

23. McCarthy AJ, Witney AA, Gould KA, Moodley A, Guardabassi L, Voss A, Denis $O$, Broens EM, Hinds J, Lindsay JA: The distribution of mobile genetic elements (MGEs) in MRSA CC398 is associated with both host and country. Genome Biol Evol 2011, 3:1164-1174.

24. Weigel LM, Clewell DB, Gill SR, Clark NC, McDougal LK, Flannagan SE, Kolonay JF, Shetty J, Killgore GE, Tenover FC: Genetic analysis of a highlevel vancomycin-resistant isolate of Staphylococcus aureus. Science 2003, 302:1569-1571.

25. Zhu W, Clark NC, McDougal LK, Hageman J, McDonald LC, Patel JB: Vancomycin-resistant Staphylococcus aureus isolates associated with Inc18-like vanA plasmids in Michigan. Antimicrob Agents Chemother 2008 52:452-457.

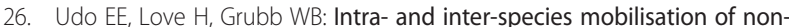
conjugative plasmids in staphylococci. J Med Microbiol 1992, 37:180-186.

27. Sung JM, Lloyd DH, Lindsay JA: Staphylococcus aureus host specificity: comparative genomics of human versus animal isolates by multi-strain microarray. Microbiology 2008, 154:1949-1959.

28. Witney AA, Marsden GL, Holden MT, Stabler RA, Husain SE, Vass JK, Butche PD, Hinds J, Lindsay JA: Design, validation, and application of a sevenstrain Staphylococcus aureus PCR product microarray for comparative genomics. Appl Environ Microbiol 2005, 71:7504-7514.

doi:10.1186/1471-2180-12-104

Cite this article as: McCarthy and Lindsay: The distribution of plasmids that carry virulence and resistance genes in Staphylococcus aureus is lineage associated. BMC Microbiology 2012 12:104.

\section{Submit your next manuscript to BioMed Central and take full advantage of:}

- Convenient online submission

- Thorough peer review

- No space constraints or color figure charges

- Immediate publication on acceptance

- Inclusion in PubMed, CAS, Scopus and Google Scholar

- Research which is freely available for redistribution 